\title{
Compression Effects on Pressure Loss in Flexible HVAC Ducts
}

\author{
Bass Abushakra, Ph.D. \\ Member ASHRAE
}

\author{
lain S. Walker, Ph.D. \\ Member ASHRAE
}

\author{
Max H. Sherman, Ph.D. \\ Fellow ASHRAE
}

\begin{abstract}
A study was conducted to evaluate the effect of compression on pressure drop in flexible, spiral wire helix core ducts used in residential and light commercial applications. Ducts of 6", 8" and 10" (150, 200 and $250 \mathrm{~mm})$ nominal diameters were tested under different compression configurations following ASHRAE Standard 120-1999 Methods of Testing to Determine Flow Resistance of HVAC Air Ducts and Fittings. The results showed that the available published references tend to underestimate the effects of compression. The study demonstrated that moderate compression in flexible ducts, typical of that often seen in field installations, could increase the pressure drop by a factor of four, while further compression could increase the pressure drop by factors close to ten. The results proved that the pressure drop correction factor for compressed ducts cannot be independent of the duct size, as suggested by ASHRAE Fundamentals, and therefore a new relationship was developed for better quantification of the pressure drop in flexible ducts. This study also suggests potential improvements to ASHRAE Standard 120-1999 and provides new data for duct design.
\end{abstract}

\section{INTRODUCTION}

In field studies, observed pressure drops in flexible duct systems are often higher than expected based on design calculations. This is because the flexible ducts are not installed in a fully stretched condition; they are often found to be compressed to varying degrees. This common problem leads to excessive pressure drop in many systems with associated increases in fan power, flow reduction, and noise. For design purposes and for diagnostics of duct systems, friction charts and friction loss equations and coefficients from various references are used. For fully stretched flexible duct, in particular, ASHRAE Fundamentals (ASHRAE 2001a) and ACCA Manual D (ACCA 1995) provide pressure drop calculations using such charts, equations and coefficients.

The 2001 ASHRAE Fundamentals (ASHRAE 2001a), Chapter 34, Duct Design, suggests the use of the Darcy friction loss equation (Equation 1) with the Altshul-Tsal equation of friction factor (Equation 2) (Altshul and Kiselev 1975, and Tsal 1989), rather than providing a friction chart, for the calculation of pressure drop in flexible ducts:

$$
\begin{array}{ll}
\Delta P_{f}=\frac{12 f L}{D} \rho\left(\frac{V}{1097}\right)^{2} & \left(\text { SI: } \Delta P_{f}=\frac{f L}{D} \rho \frac{V^{2}}{2}\right) \\
f^{\prime}=0.11\left(\frac{12 \varepsilon}{D}+\frac{68}{R e}\right)^{0.25} & \left(\text { SI: } f^{\prime}=0.11\left(\frac{\varepsilon}{D}+\frac{68}{R e}\right)\right. \\
\text { If } f^{\prime} \geq 0.018: \quad f=f^{\prime} & \\
\text { If } f^{\prime}<0.018: f=0.85 f^{\prime}+0.0028 &
\end{array}
$$

The problem with using the above equations is in estimating the correct value of the absolute roughness, $\varepsilon$, because roughness data for flexible ducts are generally not available. ASHRAE Fundamentals categorizes the roughness in five categories (smooth, medium smooth, average, medium average, and rough) and provides a general absolute roughness value for each category. It also provides a range for the roughness of each type of duct in each

Bass Abushakra is a Post Doctoral Fellow, Iain S. Walker is a Staff Scientist, and Max H. Sherman is a Senior Staff Scientist and the Group Leader of the Energy Performance of Buildings Group, Indoor Environment Department, Lawrence Berkeley National Laboratory. 
category. Flexible duct, "all types of fabric and wire", are classified as rough, with the absolute roughness range as $0.0035-0.015 \mathrm{ft}(1.0-4.6 \mathrm{~mm})$ when fully extended. As values within this wide range vary by a factor of four, the calculated friction factor (Equation 2) and the resulting pressure drop (Equation 1) could vary by $30 \%$.

On the other hand, ACCA Manual D (ACCA 1995) provides a friction chart for flexible, spiral wire helix core ducts. There are conditions for using the chart, such as maximum air velocity and temperature and positive and negative pressure, but there is no indication of whether the chart was established for "fully extended" ducts.

However, when it comes to the compression effects on flexible ducts, the available literature does not provide enough resources for an adequate estimate of pressure drop in a duct system. ASHRAE Fundamentals provides a graph, Figure 1, showing how compressing a fully stretched flexible duct increases the pressure drop; a single graph is used for all sizes of flexible ducts. To calculate the pressure drop in a compressed flexible duct, the graph provides a correction factor as a function of the duct length, that can be multiplied by the pressure drop that would occur in a fully stretched duct case.

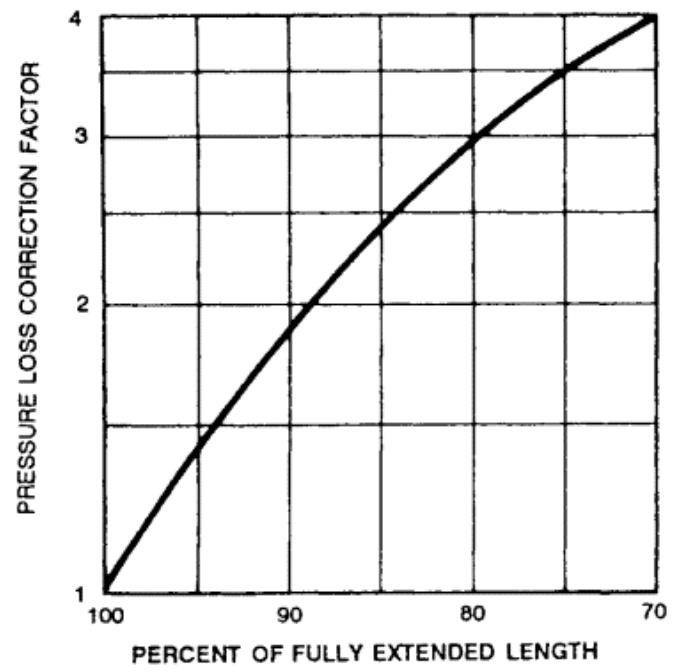

Figure 1 ASHRAE Fundamentals (2001a) (Figure 8, p.34.8) correction factor for unextended flexible duct. Copyright 2001, American Society of Heating, Refrigerating and Air-Conditioning Engineers, Inc. 1791 Tullie Circle, NE, Atlanta, GA 30329, 404-636-8400, www.ashrae.org. Reprinted by permission from 2001 ASHRAE Handbook - Fundamentals.

When the flexible duct is compressed, the core gets crumpled and the effective surface roughness increases by orders of magnitude above the range provided in ASHRAE Fundamentals. Equation 2 is not applicable to the high roughness region (on a Moody chart) where the friction factor becomes independent of the Reynolds Number (i.e., with typical $R e$ ranges encountered in an HVAC ducting system; $\left.2 \times 10^{4}<R e<5 \times 10^{4}\right)$. In this case, another model for fully-rough flow regime in pipes (ducts) found in ASHRAE Fundamentals Chapter 2 (Fluid Flow) (ASHRAE 2001a) would be more appropriate:

$$
\left.\frac{1}{\sqrt{f}}=1.14+2 \log \left(\frac{D}{12 \varepsilon}\right) \quad \text { (SI: } \frac{1}{\sqrt{f}}=1.14+2 \log \left(\frac{D}{\varepsilon}\right)\right)
$$

The problem remains that, for a designer, even using an appropriate model for the friction factor and surface roughness, such as in Equation 3, would be problematic, since having the appropriate value of the roughness for the specific compression case of the flexible duct is not available in the literature.

An experimental study on flexible spiral wire helix core ducts (of sizes commonly used in residential and light commercial buildings) was conducted at the Energy Performance of Building group (EPB) duct research facilities at Lawrence Berkeley National Laboratory (LBNL) in order to address and quantify the compression effects on the pressure drop, and to compare results with existing body of work when possible. To that end, the results were compared with pressure drop calculations in ASHRAE Fundamentals (2001a) and ACCA Manual D (ACCA 1995). 
The tests were conducted according to the test methods in the ASHRAE Standard 120-1999 - Methods of Testing to Determine Flow Resistance of HVAC Air Ducts and Fittings (ASHRAE 2001b), and included experiments on duct specimens that were less than fully stretched, in an attempt to mimic the real configurations found in a typical house or a light commercial building.

\section{METHODOLOGY}

This study on the compression effect of flexible ducts is part of larger study conducted at LBNL (Abushakra et al. 2002) to evaluate whether component test data can be reliably used in an entire system analysis. Among tests on different components of residential air distribution systems, individual experiments were conducted on flexible duct of different diameters and under different compression ratios. The flexible duct study focused on the nominal 6", 8 ", and 10" $(150,200$ and $250 \mathrm{~mm})$ diameters only, since in a typical house these three sizes constitute the majority of ducting, and thus have a major effect on the total pressure drop in the system. Figure 2 shows the test apparatus used in all the flexible duct tests.

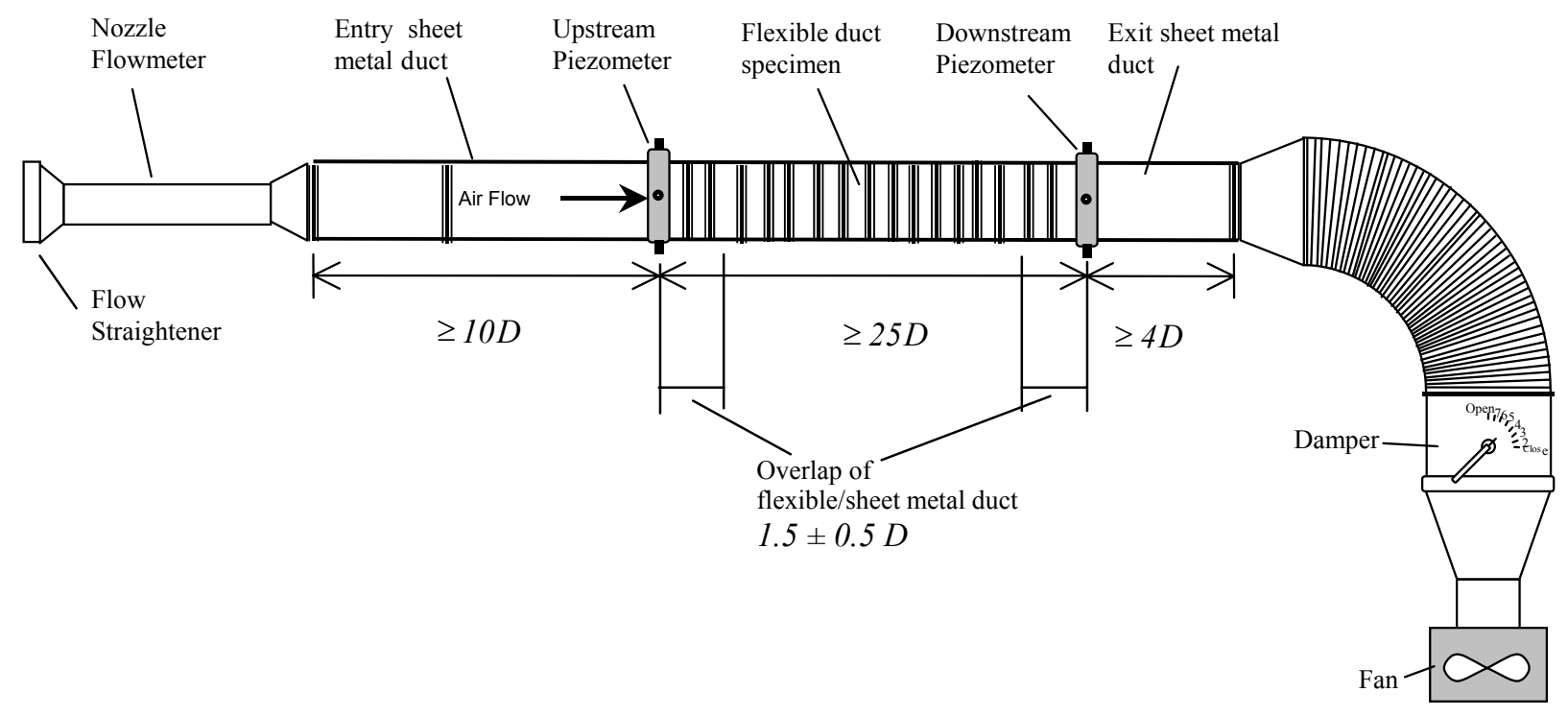

Figure 2 Schematic of the tests apparatus.

The tests apparatus included an upstream nozzle flowmeter, an entry and an exit straight sheet metal duct pieces holding the upstream and downstream piezometers, and a flexible connection to the draw-through fan. A flow straightener was added at the entry of the highly accurate nozzle flowmeter ( $\pm 0.5 \%$ accuracy). Each piezometer had four equidistant pressure taps manifolded together for a single reading; the four pressure taps provided individual readings within $1 \%$ difference with the average. The fan was equipped with a damper to modulate the flow. The flexible duct was taped to the laboratory floor to ensure a straight layout. This is of particular concern when the duct is restricted at both ends and compressed, because it tends to bulge in the middle.

The tests for each duct size and compression configuration were conducted by recording the values of the volumetric flow rate and static pressure drop in the test specimen. A data acquisition system sampled five-secondaverage readings of the flow and static pressure drop measurements. Every data point (volumetric flow rate and static pressure drop) used in the analysis was an average of 60 five-second readings. The 60 values for each data point used in the analysis were always taken after reaching a steady state flow condition.

The static pressure drop in the flexible duct specimen was obtained by subtracting the static pressure drop in the straight sheet metal duct section holding the piezometers upstream and downstream (the overlap sections), from the total value of the static pressure drop between the upstream and downstream piezometers. For improved accuracy, we performed separate tests to measure the pressure drop for the sheet metal duct sections. We found that the sheet metal duct results were within 3\% of those published by ASHRAE (ASHRAE 2001a). Abushakra et al. (2002) show the detailed calculation for the sheet metal ducts. The volumetric flow rate values were corrected to account 
for the following: (1) changing air temperatures throughout the test (corrected to start-of-test temperature), (2) calibration temperature of the flowmeter, and (3) air density changes with elevations above sea-level.

\section{Fully Stretched Flexible Duct}

The fully stretched duct has the inner core pulled tight resulting in a relatively smooth inner duct surface. This is rarely found in houses, because it results in ducts which are hard to keep attached to the fittings due to the longitudinal force required to stretch the duct. Fully stretched flexible ducts were tested first in order to establish a baseline for comparison to compressed cases. The fully-stretched specimens were at least 35 diameters long, satisfying the minimum 25-diameter-length suggested by Standard 120-1999 for fully developed flow. A 35diameter-length specimen can be compressed by as much as $30 \%$ and still satisfies the 25 -diameter overall length constraint. Nevertheless, even with a 25-diameter-length specimen, part of the duct will experience a developing flow; for instance, at the attachments to the sheet metal duct carrying the piezometers upstream and downstream of the flexible duct specimen. Allowing the flow exponent of the power-law model (pressure drop vs. volumetric flow rate) to vary in the analysis can account for effects of these developing flow regions on pressure drop.

It is important to note that the term "fully stretched" means that the inner liner of the duct is fully stretched. The flexible duct consists of three layers: (1) outer plastic layer, (2) R-4.2 (RSI-0.74) fiberglass insulation, and (3) inner liner which is a thin plastic layer with embedded spiral wire, called "core". For testing purposes, it is possible to observe what appears to be a fully stretched duct from the exterior, hiding less than fully stretched inner liner. Therefore, we ensured that the inner liner of the specimen was stretched to its full extent before every "fully stretched" test.

Clamping the test specimen Since we followed ASHRAE Standard 120-1999 for conducting our tests, we applied its "Annex E - Flexible Duct Setup Guide" stating that “......Two wraps of duct tape and a clamp shall be used to secure the test duct connections and make an airtight connection". When a specimen is cut to length, the outer layer and the insulation lengths do not correspond, necessarily, to a fully stretched inner liner. Thus clamping the whole flexible duct (its three layers), as required by Standard 120-1999, on the inlet and outlet straight sections of rigid duct (where the piezometers are placed) could cause a situation where the outer layers are fully stretched, and the inner liner is not. For example, in one 8 " $(200 \mathrm{~mm})$ diameter duct sample that we tested, we experienced such a situation in which the exterior appeared to be "fully stretched" while the core was found to be $4 \%$ compressed. The standard test procedure should be revised to require a tight connection of the inner liner only of the test specimen with enough duct tape to the rigid duct, without clamping the outer layers (insulation and outer plastic sheet).

Figure 3 shows the exterior of the test specimens of the fully stretched and the compressed 10 " $(250 \mathrm{~mm})$ duct. Lateral constraints were used in all tests to prevent movement during the test.
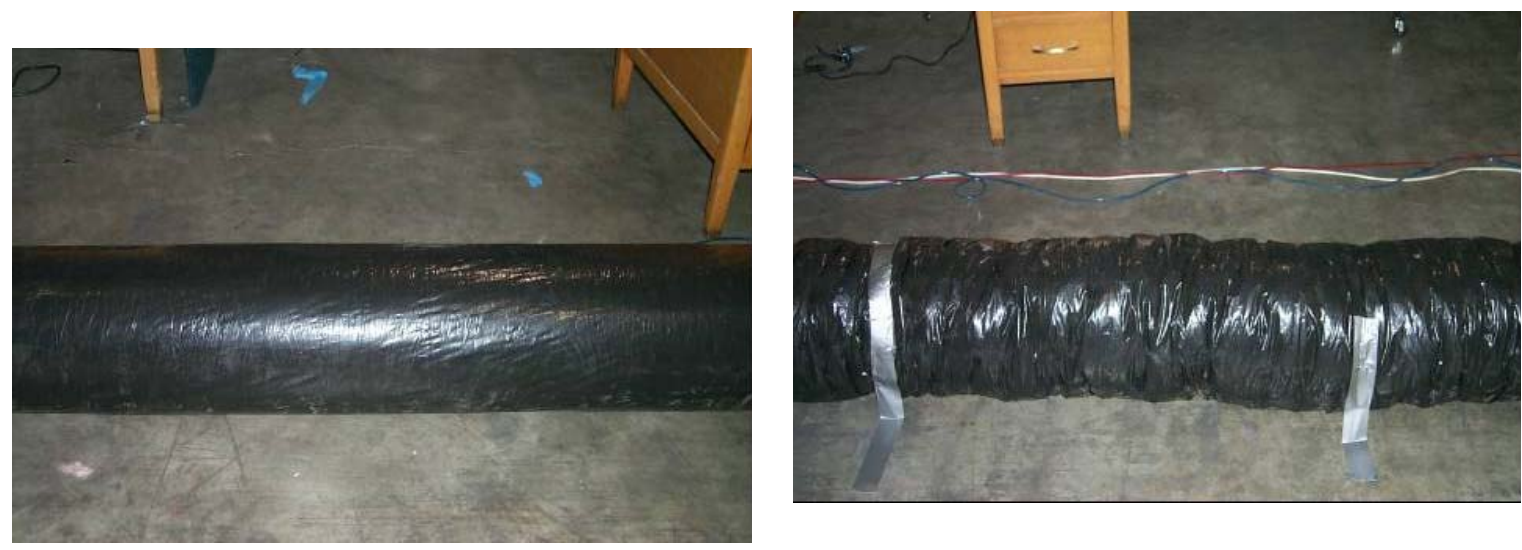

Figure 3 The exterior of the fully stretched, and the compressed (29.50\%) 10" (250 mm) flexible duct test specimens. 


\section{Compressed Flexible Duct}

The compression ratios are calculated relative to the fully stretched case. The compression ratio is the change in length divided by the fully stretched length. A maximum compression ratio of $30 \%$ was achieved for the three duct sizes. Above this compression ratio, it was not possible to keep the compressed specimen straight, because it would bulge somewhere between the upstream and downstream piezometers. This bulging is caused by restrictions due to the outer liner and the insulation of the flexible duct. In our tests, a compression of around $15 \%$ was used as a moderate compression case typically found in field installation and represents a "Normal Stretch" flexible duct scenario; a compression of around $30 \%$ would be an extreme compression case and represents a "Compressed" flexible duct scenario.

\section{RESULTS}

In all the tests, the volumetric flow rate ranges were chosen to represent ranges that are encountered in residential and light commerical buildings. Table 1 summarizes the flow conditions ranges achieved in the tests together with the actual and target compression ratios.

TABLE 1

Flow Condition Ranges in the Flexible Duct Study.

\begin{tabular}{|c|c|c|c|c|c|c|c|}
\hline $\begin{array}{c}\text { Nominal } \\
\text { Diameter } \\
\text { in } \\
(\mathrm{mm})\end{array}$ & $\begin{array}{l}\text { Compres- } \\
\text { sion } \\
\text { Scenario }\end{array}$ & $\begin{array}{c}\text { Target } \\
\text { Compres- } \\
\text { sion } \\
\text { Ratio }\end{array}$ & $\begin{array}{c}\text { Actual } \\
\text { Compres- } \\
\text { sion } \\
\text { Ratio } \\
\mathbf{r}_{\mathbf{c}}\end{array}$ & $\begin{array}{c}\text { Corrected } \\
\text { Volumetric } \\
\text { Flow Rate } \\
\text { cfm } \\
(\mathrm{L} / \mathrm{s})\end{array}$ & $\begin{array}{l}\text { Static Pressure } \\
\text { Drop } \\
\text { in water/100ft } \\
(\mathbf{P a} / \mathbf{m})\end{array}$ & $\begin{array}{c}\text { Bulk } \\
\text { Velocity } \\
\text { fpm } \\
(\mathbf{m} / \mathbf{s})\end{array}$ & $\begin{array}{l}\text { Reynolds } \\
\text { Number }\end{array}$ \\
\hline \multirow[t]{3}{*}{$(150)^{6}$} & $\begin{array}{c}\text { Fully } \\
\text { Stretched }\end{array}$ & 0 & 0 & $\begin{array}{r}90-430 \\
(41-202)\end{array}$ & $\begin{array}{c}0.08-1.98 \\
(0.7-16.2)\end{array}$ & $\begin{array}{c}447-2176 \\
(2.3-11.1)\end{array}$ & $24000-115000$ \\
\hline & $\begin{array}{l}\text { Normal } \\
\text { Stretch }\end{array}$ & 0.15 & 0.138 & $\begin{array}{r}80-400 \\
(38-189)\end{array}$ & $\begin{array}{c}0.30-6.63 \\
(2.5-54.2)\end{array}$ & $\begin{array}{c}415-2040 \\
(2.1-10.4)\end{array}$ & $22000-108000$ \\
\hline & Compressed & 0.30 & 0.286 & $\begin{array}{r}90-390 \\
(41-182)\end{array}$ & $\begin{array}{c}0.72-12.36 \\
(5.9-101.0)\end{array}$ & $\begin{array}{c}439-1966 \\
(2.2-10.0)\end{array}$ & $23000-104000$ \\
\hline \multirow[t]{3}{*}{$\begin{array}{c}8 \\
(200)^{8}\end{array}$} & $\begin{array}{c}\text { Fully } \\
\text { Stretched }\end{array}$ & 0 & 0 & $\begin{array}{l}110-480 \\
(50-225)\end{array}$ & $\begin{array}{l}0.02-0.41 \\
(0.2-3.4)\end{array}$ & $\begin{array}{r}303-1364 \\
(1.5-6.9)\end{array}$ & $21000-97000$ \\
\hline & $\begin{array}{l}\text { Normal } \\
\text { Stretch }\end{array}$ & 0.15 & 0.146 & $\begin{array}{l}100-470 \\
(48-221)\end{array}$ & $\begin{array}{c}0.08-1.65 \\
(0.7-13.5)\end{array}$ & $\begin{array}{r}292-1340 \\
(1.5-6.8)\end{array}$ & $21000-95000$ \\
\hline & Compressed & 0.30 & 0.238 & $\begin{array}{l}110-470 \\
(54-220)\end{array}$ & $\begin{array}{c}0.16-2.46 \\
(1.32-20.1)\end{array}$ & $\begin{array}{r}326-1333 \\
(1.7-6.8)\end{array}$ & $23000-94000$ \\
\hline \multirow[t]{3}{*}{$\begin{array}{r}10 \\
(250)\end{array}$} & $\begin{array}{c}\text { Fully } \\
\text { Stretched }\end{array}$ & 0 & 0 & $\begin{array}{l}150-450 \\
(73-211)\end{array}$ & $\begin{array}{c}0.02-0.14 \\
(0.1-1.2)\end{array}$ & $\begin{array}{c}282-821 \\
(1.4-4.2) \\
\end{array}$ & $25000-73000$ \\
\hline & $\begin{array}{l}\text { Normal } \\
\text { Stretch }\end{array}$ & 0.15 & 0.148 & $\begin{array}{l}130-450 \\
(63-213)\end{array}$ & $\begin{array}{l}0.04-0.48 \\
(0.4-3.9)\end{array}$ & $\begin{array}{r}247-826 \\
(1.3-4.2)\end{array}$ & $22000-73000$ \\
\hline & Compressed & 0.30 & 0.295 & $\begin{array}{l}130-460 \\
(62-217)\end{array}$ & $\begin{array}{l}0.07-0.78 \\
(0.5-6.3)\end{array}$ & $\begin{array}{c}240-843 \\
(1.2-4.3)\end{array}$ & $21000-75000$ \\
\hline
\end{tabular}

The first step in the analysis was to develop the static pressure drop model as a function of the volumetric flow rate (both variables being measured quantities). A power-law model (Equation 4) was used that allows for variations (for instance, due to boundary layer development or Reynolds Number effects) from the standard assumption of volumetric flow rate being proportional to the square root of the static pressure drop:

$$
\triangle P=C Q^{n}
$$

The static pressure drop, in this study, is calculated per unit length. ASHRAE Standard 120-1999 expresses the static pressure drop per unit length as a function of the calculated bulk velocity, rather than the volumetric flow rate, with a power-law model similar to Equation 4.

The test on the 10 " $(250 \mathrm{~mm})$ duct was repeated three times with two different sizes of nozzle flowmeter and three different lengths of specimens to examine repeatability effects. The coefficient of variation (RMS error divided by the mean) among repeated tests in the power-law model for the fully stretched 10 " duct case was $5 \%$. 
The tests on the 8 " $(200 \mathrm{~mm})$ duct were repeated twice because the 8 " $(200 \mathrm{~mm})$ specimen in the first "fully stretched" case gave doubtful results and was eventually found to be in fact compressed by $4 \%$.

The results of the experimental study are shown in Table 2. For each duct size tested, and for each compression scenario, the table reports the pressure drop coefficient and the flow exponent along with their upper and lower confidence limits, in addition to comparison from available references. The "normal stretch" and "compressed" scenarios corresponded to a compressed specimen length of around 25 and 30 diameters. The pressure drop

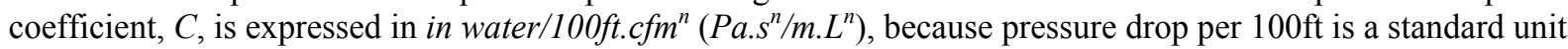
used in existing design calculation procedures.

The flow exponent, $n$, of fully developed turbulent flow has a theoretical upper limiting value of 2 . The results showed that, in all the cases studied, the flow exponent was found to be slightly lower than 2 . This indicates that any developing turbulent flow in the test specimens had a very small contribution. However, taking into consideration the confidence interval of all the calculated flow exponent values, in six out of nine cases ( 8 " and 10 " (200 and $250 \mathrm{~mm}$ ) ducts), the upper limit of the confidence interval would slightly exceed the 2 value. The confidence intervals could have been reduced by sampling more data pairs in the test (i.e., more volumetric-flowrate/static pressure-drop stations). In our tests, we took 16 data pairs in the $6 "(150 \mathrm{~mm})$ duct tests, then we reduced the tests to only four data points for the 8 " and 10" (200 and $250 \mathrm{~mm}$ ) ducts (only three data points are necessary to develop a power-law model), resulting in larger confidence intervals for the 8 " and 10 " tests.

The experimental results were compared to data in ACCA Manual D (ACCA 1995) (widely used for residential duct sizing). The ACCA manual provides a look-up friction chart for flexible, spiral wire helix core ducts. We assumed that the ACCA chart applies to a fully stretched configuration (there is no explicit definition of the compression configuration in the chart's footnote, nor in the text). Thus, to compare our results with the available references, we multiplied the values provided in ACCA by the correction factors provided in ASHRAE (2001a).

TABLE 2

Power-Law Coefficients of Three Sizes of Flexible Ducts and Comparison with Resulting Static Pressure Drop from Available References.

\begin{tabular}{|c|c|c|c|c|c|c|c|c|}
\hline $\begin{array}{c}\text { Nominal } \\
\text { Diameter } \\
\text { in } \\
(\mathrm{mm})\end{array}$ & $\begin{array}{c}\text { Compression } \\
\text { Ratio } \\
\mathbf{r}_{\mathbf{c}}\end{array}$ & 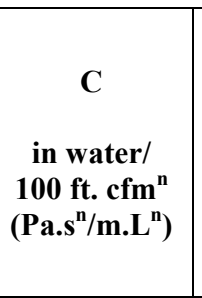 & $\begin{array}{c}\text { Lower } 95 \% \\
\text { CL of C } \\
\\
\text { in water/ } \\
100 f t . \text { cfm }^{n} \\
\left(\text { Pa.s } / \text { m.L }^{\text {n }}\right)\end{array}$ & $\begin{array}{c}\text { Upper 95\% } \\
\text { CL of C } \\
\\
\text { in water/ } \\
\text { 100ft. cfm } \\
\left(P a . s^{n} / m^{n} \cdot L^{n}\right)\end{array}$ & $\mathbf{n}$ & $\begin{array}{l}\text { Lower } \\
95 \% \\
\text { CL } \\
\text { of } \mathbf{n}\end{array}$ & $\begin{array}{l}\text { Upper } \\
95 \% \\
\text { CL } \\
\text { of n }\end{array}$ & $\begin{array}{c}\text { ACCA- } \\
\text { ASHRAE } \\
\text { Static } \\
\text { Pressure } \\
\text { Drop* } \\
\text { Average } \\
\text { Over/Under- } \\
\text { prediction } \\
\end{array}$ \\
\hline \multirow[t]{3}{*}{$\begin{array}{l}{ }^{6} \\
(150)^{6}\end{array}$} & 0 & $\begin{array}{r}1.20 \mathrm{E}-05 \\
(2.08 \mathrm{E}-04) \\
\end{array}$ & $\begin{array}{r}1.07 \mathrm{E}-05 \\
(1.86 \mathrm{E}-04) \\
\end{array}$ & $\begin{array}{r}1.34 \mathrm{E}-05 \\
(2.33 \mathrm{E}-04) \\
\end{array}$ & 1.98 & 1.96 & 2.00 & $+11 \%$ \\
\hline & 0.138 & $\begin{array}{r}6.04 \mathrm{E}-05 \\
(1.05 \mathrm{E}-03)\end{array}$ & $\begin{array}{r}5.27 \mathrm{E}-05 \\
(9.12 \mathrm{E}-04)\end{array}$ & $\begin{array}{r}6.94 \mathrm{E}-05 \\
(1.20 \mathrm{E}-03)\end{array}$ & 1.94 & 1.92 & 1.97 & $-28 \%$ \\
\hline & 0.286 & $\begin{array}{r}1.56 \mathrm{E}-04 \\
(2.70 \mathrm{E}-03) \\
\end{array}$ & $\begin{array}{r}1.32 \mathrm{E}-04 \\
(2.29 \mathrm{E}-03) \\
\end{array}$ & $\begin{array}{r}1.84 \mathrm{E}-04 \\
(3.18 \mathrm{E}-03) \\
\end{array}$ & 1.90 & 1.87 & 1.93 & $-47 \%$ \\
\hline \multirow[t]{3}{*}{$\begin{array}{r}8 \\
(200)^{8}\end{array}$} & 0 & $\begin{array}{r}3.33 \mathrm{E}-06 \\
(5.76 \mathrm{E}-05) \\
\end{array}$ & $\begin{array}{r}9.34 \mathrm{E}-07 \\
(1.62 \mathrm{E}-05) \\
\end{array}$ & $\begin{array}{r}1.19 \mathrm{E}-05 \\
(2.06 \mathrm{E}-04)\end{array}$ & 1.90 & 1.66 & 2.14 & $+39 \%$ \\
\hline & 0.146 & $\begin{array}{r}8.13 \mathrm{E}-06 \\
(1.41 \mathrm{E}-04) \\
\end{array}$ & $\begin{array}{r}5.69 \mathrm{E}-06 \\
(9.85 \mathrm{E}-05) \\
\end{array}$ & $\begin{array}{r}1.16 \mathrm{E}-05 \\
(2.01 \mathrm{E}-04) \\
\end{array}$ & 1.99 & 1.92 & 2.06 & $-8 \%$ \\
\hline & 0.238 & $\begin{array}{r}1.71 \mathrm{E}-05 \\
(2.96 \mathrm{E}-04) \\
\end{array}$ & $\begin{array}{r}8.83 \mathrm{E}-06 \\
(1.53 \mathrm{E}-04)\end{array}$ & $\begin{array}{r}3.31 \mathrm{E}-05 \\
(5.73 \mathrm{E}-04)\end{array}$ & 1.94 & 1.81 & 2.06 & $-14 \%$ \\
\hline \multirow[t]{3}{*}{$\begin{array}{r}10 \\
(250)\end{array}$} & 0 & $\begin{array}{r}7.31 \mathrm{E}-07 \\
(1.27 \mathrm{E}-05) \\
\end{array}$ & $\begin{array}{r}2.63 \mathrm{E}-07 \\
(4.55 \mathrm{E}-06) \\
\end{array}$ & $\begin{array}{r}2.03 \mathrm{E}-06 \\
(3.52 \mathrm{E}-05) \\
\end{array}$ & 1.99 & 1.80 & 2.17 & $+13 \%$ \\
\hline & 0.148 & $\begin{array}{r}2.75 \mathrm{E}-06 \\
(4.76 \mathrm{E}-05) \\
\end{array}$ & $\begin{array}{r}1.97 \mathrm{E}-06 \\
(3.41 \mathrm{E}-05)\end{array}$ & $\begin{array}{r}3.84 \mathrm{E}-06 \\
(6.65 \mathrm{E}-05) \\
\end{array}$ & 1.98 & 1.92 & 2.04 & $-15 \%$ \\
\hline & 0.295 & $\begin{array}{r}4.53 \mathrm{E}-06 \\
(7.84 \mathrm{E}-05)\end{array}$ & $\begin{array}{r}2.92 \mathrm{E}-06 \\
(5.06 \mathrm{E}-05)\end{array}$ & $\begin{array}{r}7.00 \mathrm{E}-06 \\
(1.21 \mathrm{E}-04)\end{array}$ & 1.97 & 1.89 & 2.05 & $-12 \%$ \\
\hline
\end{tabular}

* ACCA-ASHRAE values are average values of pressure drop corresponding to the flow rates used in each test, and calculated by multiplying the look-up values in ACCA Manual D Chart 7, page A2-10 (ACCA 1995) by the correction factor in ASHRAE Fundamentals (ASHRAE 2001a), Figure 8, p.34.8. For the fully stretched case $(0 \%$ compression) the correction factor is 1 . 
The ACCA chart overpredicted the pressure drop for the fully stretched duct of all sizes tested by an average of $21 \%$. For less than fully stretched specimens, ACCA, corrected with ASHRAE pressure drop correction factors, underpredicted the pressure drop by an average of $17 \%$ for the normal stretch cases (around $15 \%$ compression), and by $24 \%$ for the compressed cases (around 30\% compression). For all tests with different compression ratios, the average underprediction is $21 \%$. Without the correction with the ASHRAE factors, ACCA underpredicted all the compression cases by an average of $73 \%$. This indicates that ACCA Manual D data are probably obtained from "fully stretched to slightly compressed" flexible duct. We contacted ACCA, and they were not able to provide us with specifics on the compression ratios used to produce the chart, since the work was contracted a few years earlier, and the compression ratios were not documented.

The results of compressed ducts also showed that when a flexible duct is compressed, it can have a greater static pressure drop per unit length than a fully stretched duct of a smaller diameter. This is important to be aware of when designing and installing flexible duct systems, as available friction charts (eg. ACCA Manual D) do not show this effect.

\section{DISCUSSION}

Developing power-law models to quantify the pressure drop in flexible duct under different compression scenarios in this study facilitated establishing appropriate pressure drop correction factors for compressed flexible duct. The pressure drop correction factor, $P D C F$, is a multiplier that can be used to estimate the static pressure drop in a flexible duct when less than fully stretched, based on its static pressure drop when fully stretched:

$$
P D C F=\frac{\Delta P}{\Delta P_{F S}}
$$

where $\Delta P$ is the static pressure drop at a particular level of compression, and $\Delta P_{F S}$ is that corresponding to a fully stretched configuration. Figure 4 shows the measured $P D C F$ (Equation 5) for all the measured data.

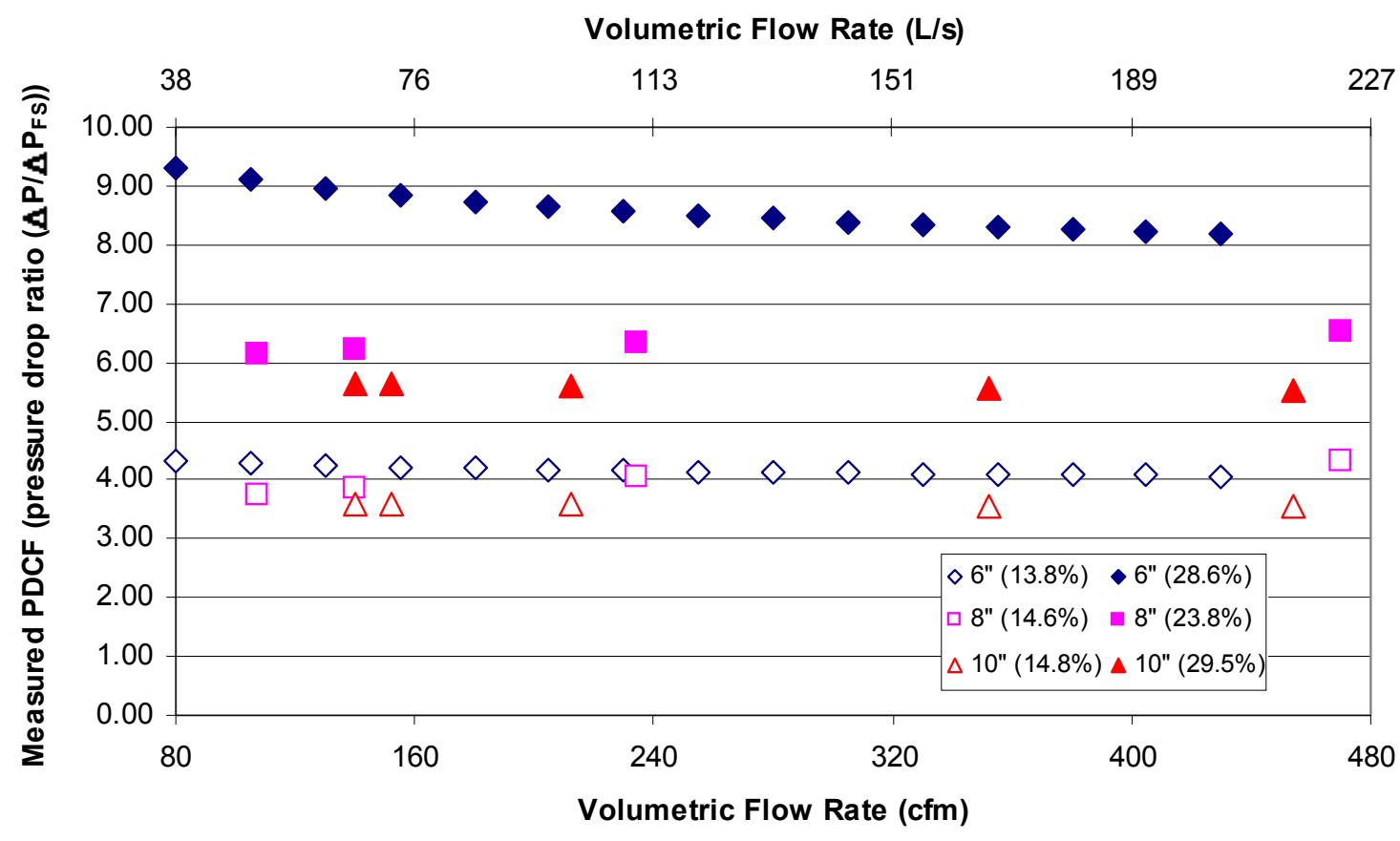

Figure 4 The "measured" pressure drop correction factor of normal stretch and compressed 6", 8", and $10 "(150,200$, and $250 \mathrm{~mm})$ flexible duct as a function of the volumetric flow rate. 
Figure 4 llustrates that the $P D C F$ is relatively constant with the flow rate, but varies with the duct diameter and the compression ratio. The figure basically shows the greater effect of compression on the pressure drop for smaller duct sizes.

Our analysis of the measured data has shown that the pressure drop correction factor, $P D C F$, is approximated well by a linear function of the compression ratio, $r_{c}$ :

$$
\begin{aligned}
& r_{c}=1-\frac{L}{L_{F S}} \\
& P D C F=1+a \times r_{c}
\end{aligned}
$$

where $P D C F$ would be equal to 1 (no correction) for a zero compression. The empirical coefficient, $a$, can be obtained from experimental data for each duct size using:

$$
a=\frac{\sum_{j=1}^{m}\left(\left(\frac{\sum_{i=1}^{k} \frac{\Delta P_{i}}{\Delta P_{F S i}}}{k}\right)-1\right)_{j}}{\sum_{j=1}^{m} r_{c_{j}}}
$$

where,

$\mathrm{k}=$ number of volumetric-flow-rate/static pressure-drop stations in a test,

$\mathrm{m}=$ number of compression cases (tests), including the fully stretched case.

The compression ratio, $r_{c}$, is calculated using Equation 6 together with the measured length of the test specimen, fully stretched $\left(L_{F S}\right)$ and under compression $(L)$. Table 3 includes the values of $r_{c}$ and the calculated coefficient $a$ obtained from the measured data.

\begin{tabular}{|c|c|c|}
\hline $\begin{array}{c}\text { Nominal Diameter } \\
\text { in } \\
(\mathrm{mm})\end{array}$ & $\begin{array}{c}\text { Compression Ratio } \\
\mathbf{r}_{\mathbf{c}}\end{array}$ & $\begin{array}{c}\text { Pressure Drop Correction Factor } \\
\text { Coefficient } \\
\text { a }\end{array}$ \\
\hline \multirow{3}{*}{$\begin{array}{c}6 \\
(150)\end{array}$} & 0 & \multirow[t]{3}{*}{25.35} \\
\hline & 0.138 & \\
\hline & 0.286 & \\
\hline \multirow{3}{*}{${ }^{8}{ }^{8}$} & 0 & \multirow[t]{3}{*}{21.61} \\
\hline & 0.146 & \\
\hline & 0.238 & \\
\hline \multirow{3}{*}{$\begin{array}{r}10 \\
(250)\end{array}$} & 0 & \multirow[t]{3}{*}{16.18} \\
\hline & 0.148 & \\
\hline & 0.295 & \\
\hline
\end{tabular}

TABLE 3

Compression Ratios and Calculated Coefficients in the PDCF of three Flexible Duct Sizes

Table 4 shows the PDCF models developed, using Equation 7, for the 6", 8", and the 10" $(150,200$, and 250 $\mathrm{mm}$ ) ducts tested. A reference model, ASHRAE-all sizes, is also listed for comparison. This reference model was obtained with a best-fit first-order polynomial $\left(P D C F=1+9.86 r_{c}\right)$, developed with look-up values from ASHRAE (2001a) (Figure 1). The model based on ASHRAE data is independent of duct size and underestimates the pressure drop by an average of $35 \%$ (with the flow conditon ranges and the duct sizes used in this study). Figure 5 shows the corresponding $P D C F$ graphs obtained using Equation 7 and the values of the coefficient $a$ in Table 3. The figure also shows the measured $P D C F$ values (Equation 5) for the three duct sizes tested, and the graph of the reference 
ASHRAE model. Each "measured" $P D C F$ value shown in the figure is an average value for all volumetric-flowrate/static pressure-drop stations in a given case.

TABLE 4

Pressure Drop Correction Factor of Three Sizes of Flexible Duct

\begin{tabular}{|c|c|}
\hline $\begin{array}{c}\text { Diameter } \\
\text { in } \\
(\mathbf{m m})\end{array}$ & $\begin{array}{c}\text { Pressure Drop Correction Factor } \\
\text { PDCF }\end{array}$ \\
\hline 6 \\
$(150)$ & $1+25.35 \mathrm{r}_{\mathbf{c}}$ \\
\hline 8 & $1+21.61 \mathrm{r}_{\mathbf{c}}$ \\
\hline$(200)$ & $1+16.18 \mathrm{r}_{\mathbf{c}}$ \\
\hline 10 & $\mathbf{1 + 9 . 8 6} \mathbf{r}_{\mathbf{c}}$ \\
\hline ASHRAE-all sizes & \\
\hline
\end{tabular}

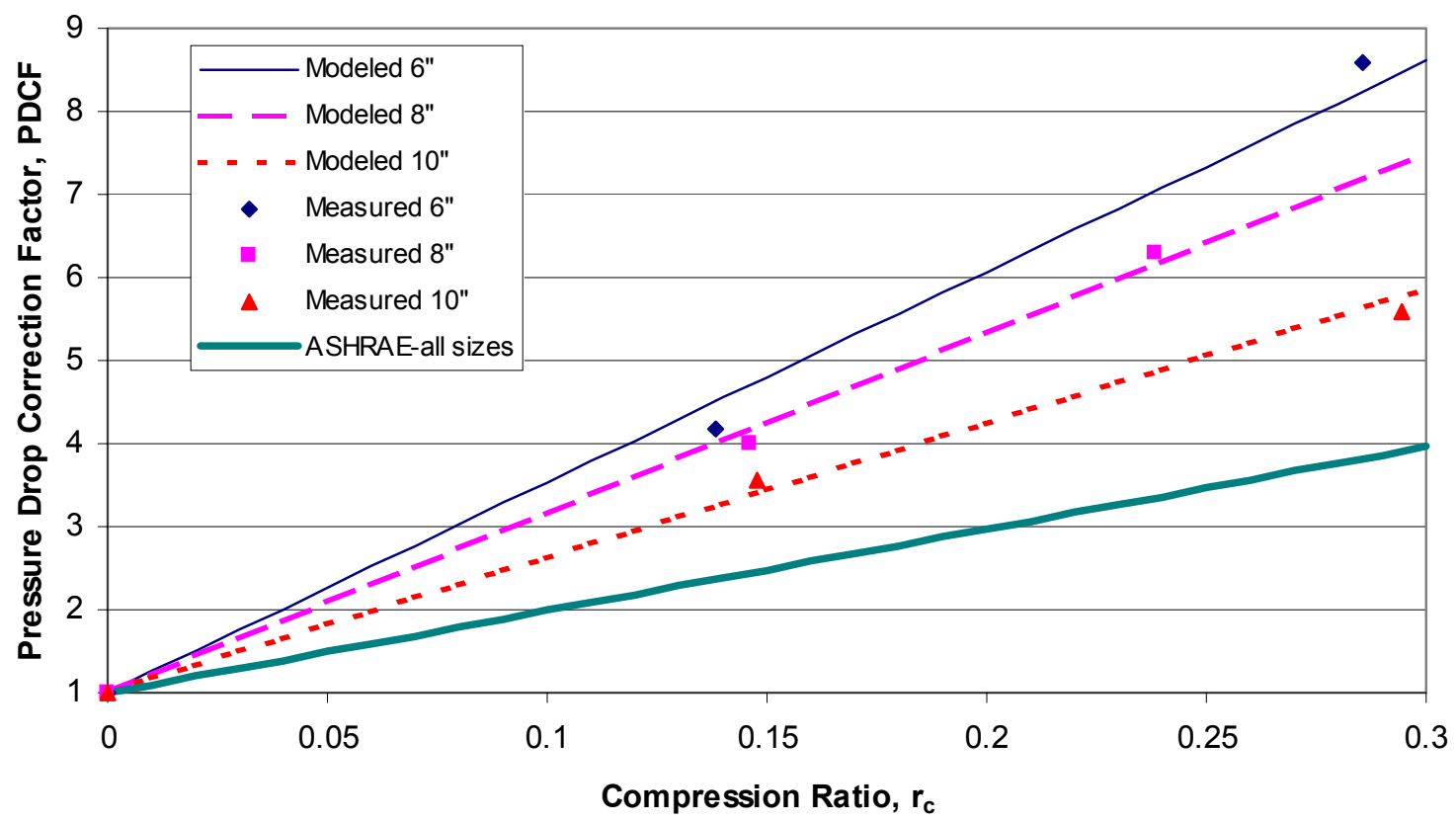

Figure 5 Comparison of the measured PDCF's and the linear models including the model of currently available ASHRAE data.

\section{Effect of Compressibility on Pitch-to-Diameter Ratio}

The physical basis of the empirical relationship for the $P D C F$ (Equation 7) can be explained in terms of change in the friction factor and the geometry of the flexible duct when compressed. Figure 6 shows a schematic of a flexible duct inner liner in fully stretched and in compressed conditions.

Fully stretched

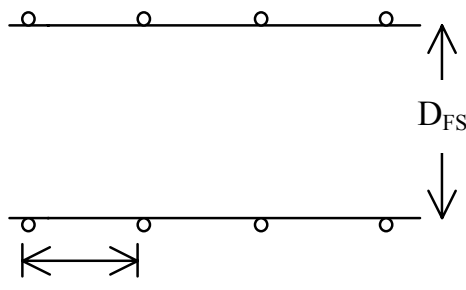

$\lambda$
Less then fully stretched

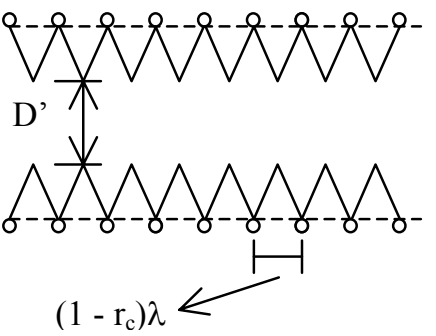


Figure 6 Schematic of the inner liner of a flexible duct.

Compressing the flexible duct results in a crumpled inner liner which reduces the effective interior crosssectional area and increases its absolute surface roughness. The pitch, $\lambda$, is the longitudinal distance between two consecutive spirals of the flexible duct. The degree of area reduction and roughness increase depends on the pitchto-diameter ratio (larger pitch leads to higher cross-sectional area changes and greater roughness). Rather than having multiple equations for calculating $P D C F$, we examined the possibility of collapsing the results into a single relationship using the duct geometry factors described above. Dividing our measured values of $a$ by the corresponding pitch-to-diameter ratio of the fully stretched duct, $\lambda_{F S} / D_{F S}$, generated values that are approximately equal, with an average value of 106. It is possible that this relationship could be used for ducts of other diameters and pitches, but tests on other ducts need to be carried out in order to confirm this possibility. The pitch-todiameter-normalized $P D C F$ values use the following expression:

$$
P D C F_{\text {Norm }}=1+106\left(\frac{\lambda_{F S}}{D_{F S}}\right) r_{c}
$$

The use of this single value had differences of less than $5 \%$ compared to all the measured points. Figure 7 shows a comparison between the raw $P D C F$ models using Equation 7 (shown in Figure 5) and the nomalized models, $P D C F_{\text {Norm }}$ (using Equation 9). The $P D C F_{\text {Norm }}$ compared with $P D C F$ overpredicts by an average of $4.4 \%$ for the 6 " $(150 \mathrm{~mm})$, underpredicts by an average of $2.0 \%$ for the 8 " $(200 \mathrm{~mm})$, and underpredicts by an average of $1.7 \%$ for the 10 " $(250 \mathrm{~mm})$ duct. These over-and-underprediction results were within the experimental uncertainties in the power-law model calculations of the pressure drop in the compressed ducts, as can be seen in Table 5 .

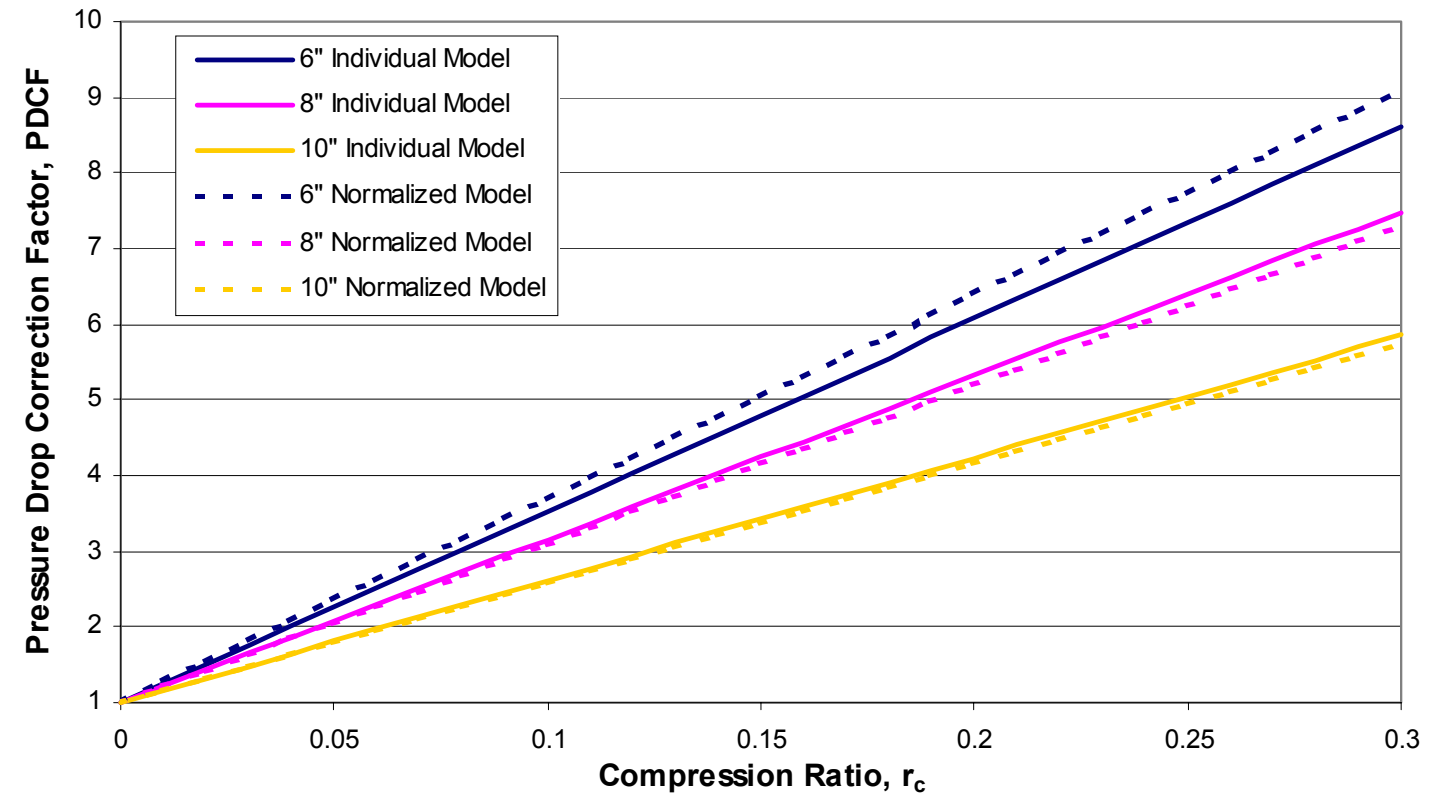

Figure 7 Comparison between the individually calculated PDCF models (Equation 7) for each duct size and those derived from the normalized model (Equation 9). 
TABLE 5

Experimental Uncertainties in the Fitted Pressure Drop Power-Law Models ${ }^{1}$ of the Compressed Flexible Ducts

\begin{tabular}{|c|c|c|c|}
\hline $\begin{array}{c}\text { Nominal } \\
\text { Diameter } \\
\text { in } \\
(\mathbf{m m})\end{array}$ & $\begin{array}{c}\text { Compression Ratio } \\
\mathbf{r}_{\mathbf{c}}\end{array}$ & $\begin{array}{c}\text { Upper 95\% Confidence } \\
\text { Limit }\end{array}$ & $\begin{array}{c}\text { Lower 95\% Confidence } \\
\text { Limit }\end{array}$ \\
\hline \multirow{2}{*}{$(150)$} & 0.138 & 5.7 & 5.4 \\
\hline \multirow{2}{*}{$(200)$} & 0.286 & 6.7 & 6.3 \\
\hline \multirow{2}{*}{$(250)$} & 0.146 & 13.9 & 7.6 \\
\cline { 2 - 4 } & 0.238 & 6.5 & 6.1 \\
\hline
\end{tabular}

1 The power -law models coefficients with their corresponding confidence limits are shown in Table 2.

Thus, by comparing its predictions with individual $P D C F$ models for each duct size (Equation 7), a single $P D C F_{\text {Norm }}$ model (Equation 9) for different duct sizes was found to be convenient for use with acceptable accuracy. Figure 8 illustrates the static pressure drop in the "compressed" 10 " $(250 \mathrm{~mm})$ duct as measured, power-law-fitted, and predicted with two different $P D C F$ models. The compression ratio was $29.5 \%$, and the measured data consisted of five volumetric-flow-rate/static pressure-drop stations, from which a power-law model of the pressure drop was developed. The predicted pressure drop models used the power-law model developed for the fully stretched case multiplied by the pressure drop correction factor. Considering the power-law-fitted results with their $95 \%$ confidence limits (CLs) as the basis for comparison, the model using PDCF (Equation 7) overpredicted the pressure drop, corresponding to the measured volumetric-flow-rate, by an average of $3 \%$, while the model using the $P D C F_{\text {Norm }}$ (Equation 9) overpredicted the pressure drop by an average of $0.7 \%$ (results within the experimental uncertainties).

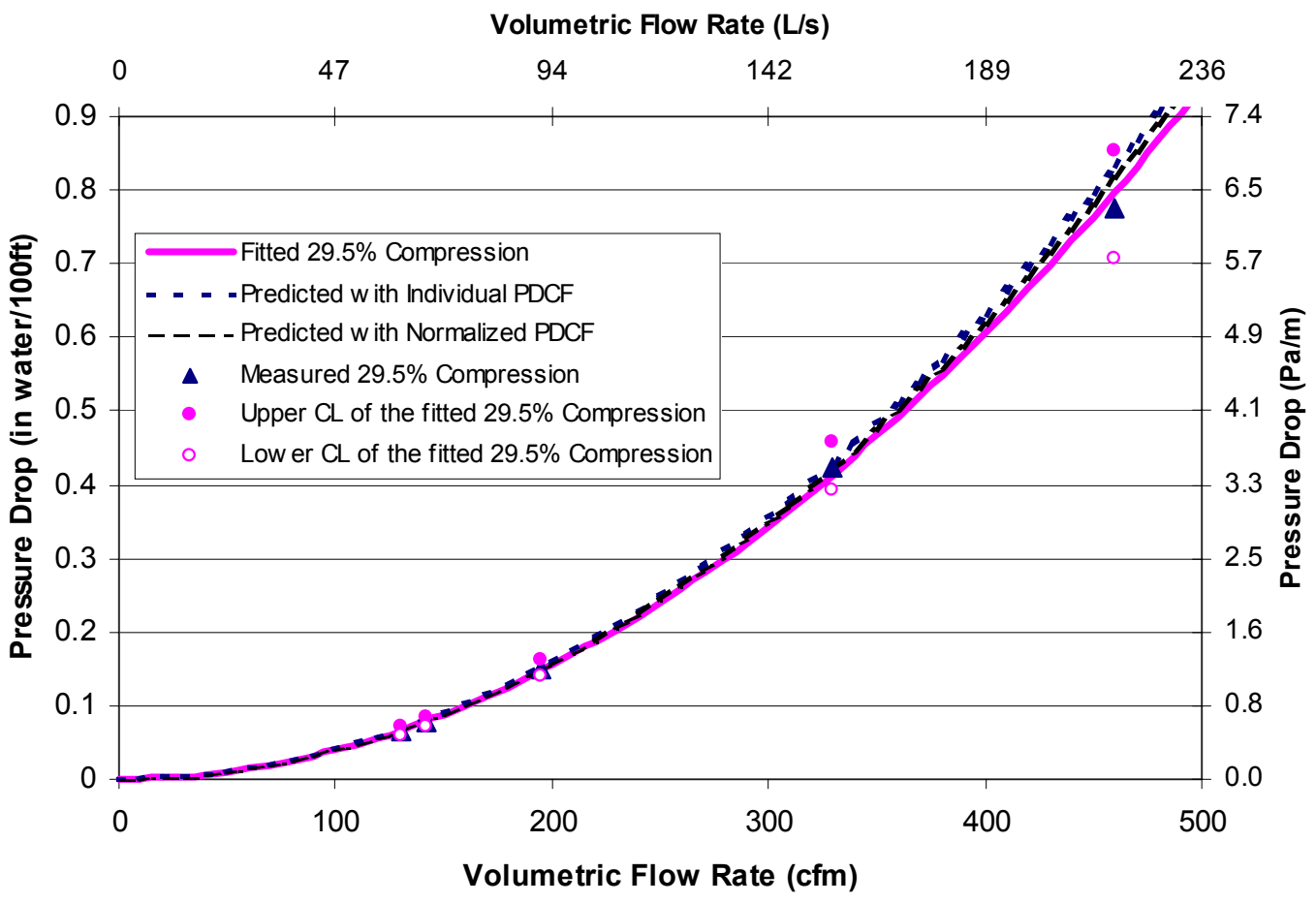


Figure 8 Comparison between measured, power-law-fitted, and predicted static pressure drop with PDCF models in a compressed $10 "(250 \mathrm{~mm})$ flexible duct.

\section{CONCLUSIONS}

Our experiments determined pressure drops for fully stretched and compressed flexible ducts. The pressure drop for fully stretched ducts was used as a baseline in developing simple pressure drop correction factors ( $P D C F)$. The $P D C F$ can be applied to the pressure drop for fully stretched duct to estimate the pressure drop in compressed ducts. The new relationship for the $P D C F$ is a function of the compression ratio and both the pitch and the nominal diameter of the duct. The $P D C F$ and the pressure drop power-law models developed in this study provide new data for duct design, and could be used by ASHRAE and ACCA to update their handbooks/manuals. The study showed that the pressure drop (flow resistance) for flexible ducts increases significantly (by factors close to 10) when the ducts are not fully stretched. Therefore it is crucial for the designer and installer to be aware of these compressibility effects and the elevated pressure drop that would affect the HVAC fan sizing. The contractor should install flexible ducts so as to reduce the compression effects. A flexible duct connecting two fittings should always be cut to an appropriate length. An excessive length would increase the pressure drop, but on the other hand, a fully-stretched duct would result in its disconnection from the fittings. The results also showed that:

- A change to the standard test procedure of flexible ducts, as an improvement to ASHRAE Standard 1201999 , is required such that only the inner liner of the test specimen is tightly connected to the rigid duct (where the peizometers measuring the pressure drop are placed) without clamping the outer layers. This modification would ensure a correct measurement of the fully stretched flexible duct pressure drop, and would facilitate the derivation of accurate pressure drop correction factors for any percentage of compression.

- The pressure drop correction factor, independent of duct size, provided by ASHRAE (ASHRAE 2001a) underestimates the pressure drop in all of the duct sizes tested, on average, by $35 \%$.

- The friction chart provided in ACCA Manual D (ACCA 1995) overpredicts the pressure drop for fully stretched duct by an average of $21 \%$. For less than fully stretched duct, ACCA values corrected with correction factors from ASHRAE Fundamentals, showed around 21\% underprediction in the pressure drop ( $73 \%$ underprediction without the ASHRAE correction).

- When a flexible duct is compressed, it can have a greater static pressure drop per unit length than a fully stretched duct of a smaller diameter.

In future work, more duct sizes should be tested in order to complete the range of duct sizes used in houses and light commercial buildings (up to $16 "(410 \mathrm{~mm})$ diameters). Further investigations should be conducted in order to quantify the absolute surface roughness of flexible duct, and to find out whether a more accurate model that relates it to the friction drop factor, $f$, can be developed. Such a study would lead to establishing a $P D C F$ model in which the physical basis for the empirical number, 106, obtained in Equation 9, can be determined.

\section{ACKNOWLEDGEMENTS}

This work at the Lawrence Berkeley National Laboratory was funded by Pacific Gas and Electric Company under Contract S9902A, to support PG\&E's energy efficiency programs in new and existing residential buildings via the California Institute for Energy Efficiency under Contract No. S9902A. Publication of research results does not imply CIEE endorsement of or agreement with these findings, nor that of any CIEE sponsor.

This work was also supported by the Assistant Secretary for Energy Efficiency and Renewable Energy, Office of Building Technology, State and Community Programs, Office of Building Research and Standards, of the U.S. Department of Energy under Contract No. DE-AC03-76SF00098.

The authors like to express a word of thanks to Darryl Dickerhoff for his contribution in designing, setting up and building the test apparatus required for the experiments, and also for his invaluable input whenever needed.

\section{NOMENCLATURE}

$a \quad=$ slope of the linear equation of the pressure drop correction factor

$C, C^{\prime}=$ pressure drop coefficient (in water $\left./ 100 \mathrm{ft} . \mathrm{cfm}^{\mathrm{n}}\right),\left(\mathrm{Pa} \cdot \mathrm{s}^{\mathrm{n}} / \mathrm{m} \cdot \mathrm{L}^{\mathrm{n}}\right)$

$D \quad=$ flexible duct diameter (in), $(\mathrm{mm})$

$D^{\prime} \quad=$ flexible duct modified diameter after compression (in), (mm) 


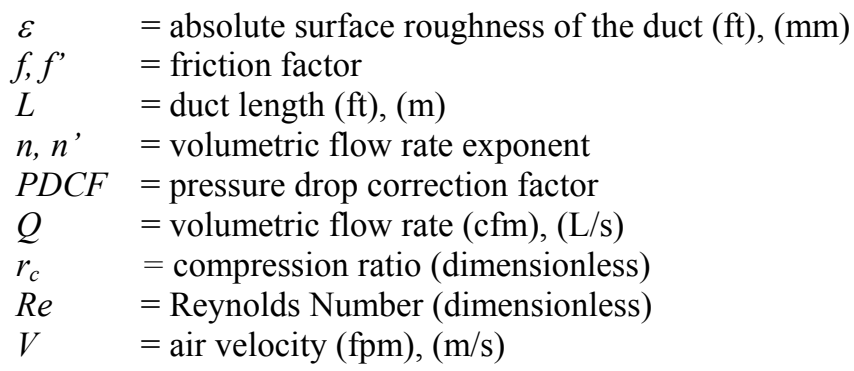

\section{Greek Symbols}

$\Delta P \quad=$ static pressure drop per unit length (in water/100 ft), $(\mathrm{Pa} / \mathrm{m})$

$\Delta P_{f} \quad=$ static pressure drop (in water), $(\mathrm{Pa})$

$\lambda \quad=$ pitch of the flexible duct (longitudinal distance between two consecutive wire spirals) (in), (mm)

$\rho \quad=$ air density $\left(\mathrm{lb} / \mathrm{ft}^{3}\right),\left(\mathrm{kg} / \mathrm{m}^{3}\right)$

\section{Subscripts}

$F S \quad=$ fully stretched

Norm = normalized

\section{REFERENCES}

Abushakra, B., Walker, I.S., and M.H. Sherman. 2002. A Study of Pressure Losses in Residential Air Distribution Systems. Proceeding of the 2002 ACEEE Summer Study on Energy Efficiency in Buildings. American Council for an Energy Efficient Economy, Washington, D.C. Also, Lawrence Berkeley National Laboratory Technical Report, LBNL-49700.

ACCA. 1995. Residential Duct Systems. Manual D. Air Conditioning Contractors of America. Washington, DC. Altshul, A.D. and P.G. Kiselev. 1975. Hydraulics and Aerodynamics. Stroisdat Publishing House, Moscow, USSR. ASHRAE. 2001a. ASHRAE Handbook of Fundamentals. American Society of Heating Refrigerating and Airconditioning Engineers, Atlanta, Georgia.

ASHRAE. 2001b. ASHRAE Standard 120-1999, Methods of Testing to Determine Flow Resistance of HVAC Air Ducts and Fittings. American Society of Heating Refrigerating and Air-conditioning Engineers, Atlanta, Georgia.

Tsal, R.J. 1989. Altshul-Tsal friction factor equation. Heating, Piping and Air Conditioning (August). 